\title{
Correction to: A retrospective analysis of weight changes in HIV- positive patients switching from a tenofovir disoproxil fumarate (TDF)- to a tenofovir alafenamide fumarate (TAF)-containing treatment regimen in one German university hospital in 2015-2017
}

\author{
Mario Gomez ${ }^{1}$. Ulrich Seybold ${ }^{1}$. Julia Roider ${ }^{1}$. Georg Härter ${ }^{2}$. Johannes R. Bogner ${ }^{1}$
}

Published online: 19 November 2018

(c) The Author(s) 2018

\section{Correction to: Infection \\ https://doi.org/10.1007/s15010-018-1227-0}

The original version of this article unfortunately contained mistakes. The presentation of Fig. 1 was incorrect and the Acknowledgements were missing. Please find the Acknowledgement here:

Acknowledgement

This work was partly supported by DZIF project $\mathrm{Tl}$ 02.001 .

The corrected figure is given below.

Open Access This article is distributed under the terms of the Creative Commons Attribution 4.0 International License (http://creativeco mmons.org/licenses/by/4.0/), which permits unrestricted use, distribution, and reproduction in any medium, provided you give appropriate credit to the original author(s) and the source, provide a link to the Creative Commons license, and indicate if changes were made.

The original article can be found online at https://doi.org/10.1007/ s15010-018-1227-0.

Mario Gomez

mariogomezcamacho@gmail.com

1 Sektion Klinische Infektiologie, Medizinische Klinik und Poliklinik IV, Klinikum der Universität, LudwigMaximilians-Universität München, Pettenkoferstrasse 8a, 80336 Munich, Germany

2 Medicover Ulm MVZ, Münsterplatz 6, 89073 Ulm, Germany 
Fig. 1 Mean change in weight in percent \pm standard deviation through 360 days for TDF and TAF separately; a results of patients after switch to TAF $(n=129)$ and $\mathbf{b}$ results of patients receiving TDF; this arm comprises 241 patients, since switch patients initially received TDF (pooled data from the switch group and control group) $\mathbf{a}$

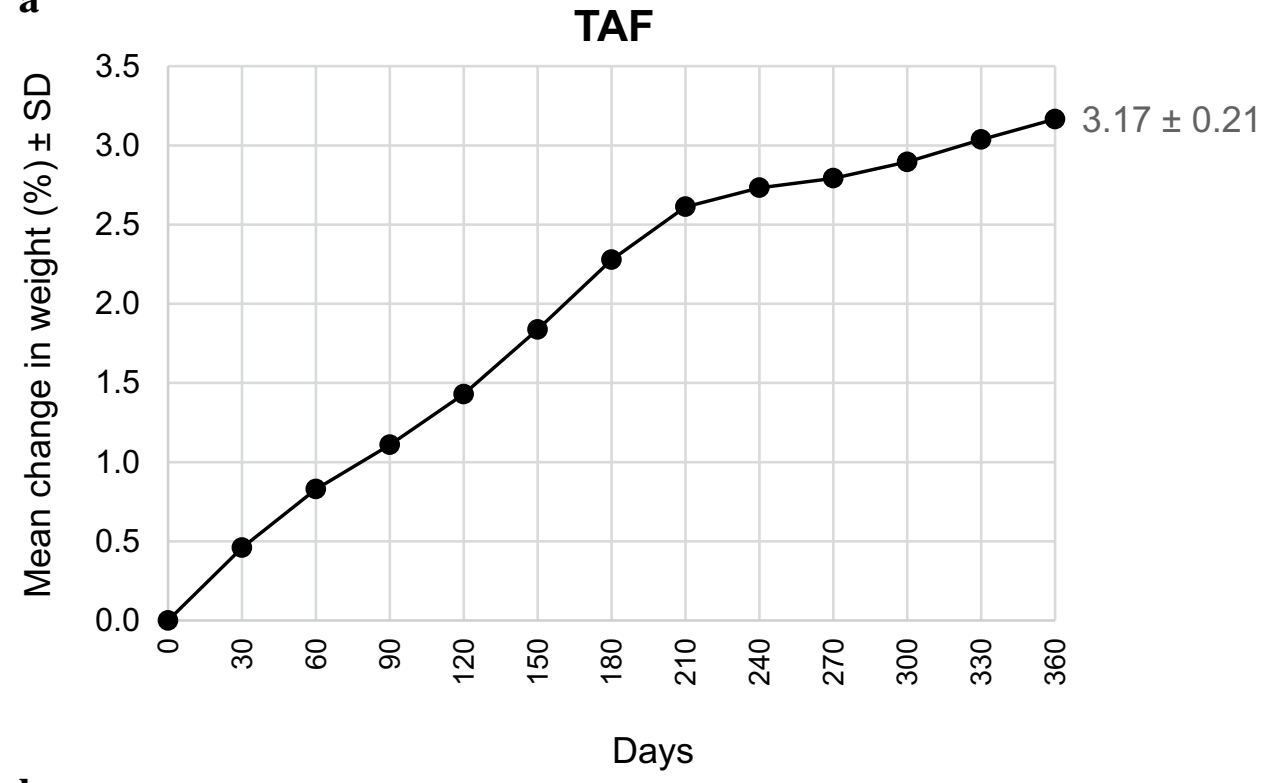

b

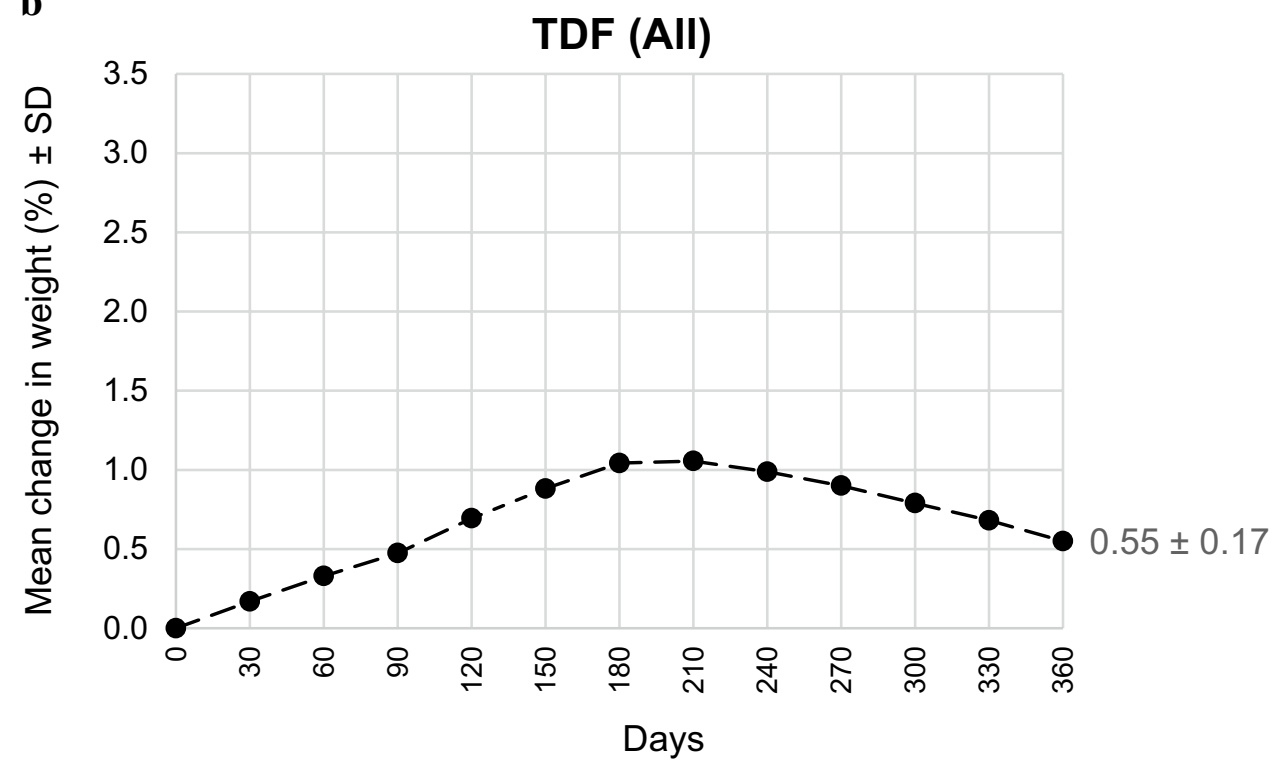

